\title{
In situ spectroscopy on intact Leptospirillum ferrooxidans reveals that reduced cytochrome 579 is an obligatory intermediate in the aerobic iron respiratory chain
}

\author{
Robert C. Blake II* and Megan N. Griff \\ College of Pharmacy, Xavier University of Louisiana, New Orleans, LA, USA
}

\section{Edited by:}

David Emerson, Bigelow Laboratory

for Ocean Sciences, USA

\section{Reviewed by:}

James Hemp, University of Illinois at Urbana-Champaign, USA

David Emerson, Bigelow Laboratory

for Ocean Sciences, USA

\section{${ }^{*}$ Correspondence:}

Robert C. Blake II, College of Pharmacy, Xavier University of Louisiana, 1 Drexel Drive, New Orleans, LA 70125, USA. e-mail: rblake@xula.edu

\begin{abstract}
Electron transfer reactions among colored cytochromes in intact bacterial cells were monitored using an integrating cavity absorption meter that permitted the acquisition of accurate absorbance data in suspensions of cells that scatter light. The aerobic iron respiratory chain of Leptospirillum ferrooxidans was dominated by the redox status of an abundant cellular cytochrome that had an absorbance peak at $579 \mathrm{~nm}$ in the reduced state. Intracellular cytochrome 579 was reduced within the time that it took to mix a suspension of the bacteria with soluble ferrous iron at $\mathrm{pH}$ 1.7. Steady state turnover experiments were conducted where the initial concentrations of ferrous iron were less than or equal to that of the oxygen concentration. Under these conditions, the initial absorbance spectrum of the bacterium observed under air-oxidized conditions was always regenerated from that of the bacterium observed in the presence of $\mathrm{Fe}(\mathrm{II})$. The kinetics of aerobic respiration on soluble iron by intact $L$. ferrooxidans conformed to the Michaelis-Menten formalism, where the reduced intracellular cytochrome 579 represented the Michaelis complex whose subsequent oxidation appeared to be the rate-limiting step in the overall aerobic respiratory process. The velocity of formation of ferric iron at any time point was directly proportional to the concentration of the reduced cytochrome 579. Further, the integral over time of the concentration of the reduced cytochrome was directly proportional to the total concentration of ferrous iron in each reaction mixture. These kinetic data obtained using whole cells were consistent with the hypothesis that reduced cytochrome 579 is an obligatory steady state intermediate in the iron respiratory chain of this bacterium. The capability of conducting visible spectroscopy in suspensions of intact cells comprises a powerful post-reductionist means to study cellular respiration in situ under physiological conditions for the organism.
\end{abstract}

Keywords: Leptospirillum ferrooxidans, electron transfer, aerobic respiration, chemolithotroph, acidophile, cytochrome 579, in situ spectroscopy, integrating sphere

\section{INTRODUCTION}

Certain chemolithotrophic bacteria inhabit ore-bearing geological formations exposed to the atmosphere and obtain all of their energy for growth from the oxidation and dissolution of minerals within the ore. Energy is derived from oxidative phosphorylation coupled to respiratory electron transfer. The ability to respire aerobically on soluble ferrous ions under strongly acidic conditions is currently known to be expressed by at least 34 species in 14 genera distributed throughout the Gram-negative (Markosyan, 1972; Huber and Stetter, 1989; Kelly and Wood, 2000; Hallberg et al., 2010), Gram-positive (Clark and Norris, 1996; Norris et al., 1996; Johnson et al., 2008, 2009; Guo et al., 2009; Jiang et al., 2009), and Archaea bacteria (Segerer et al., 1986; Huber et al., 1989; Huber and Stetter, 1991; Karavaiko et al., 1994; Golyshina et al., 2000, 2009). Given the genetic diversity within this collection of phenotypically related bacteria, it would not be surprising to learn that phylogenetically distinct groups of bacteria express different electron transfer biomolecules and pathways to accomplish aerobic respiration on soluble iron.
Classic reductionist studies that involve the structural and functional characterization of highly purified proteins in dilute solution have described a bewildering variety of different redoxactive electron transport proteins in cell-free extracts derived from iron-grown Gram-negative (Cox and Boxer, 1978; Hart et al., 1991; Blake et al., 1992; Yarzábal et al., 2002, 2004), Gram-positive (Blake et al., 1993; Takai et al., 2001; Dinarieva et al., 2010), and Archaea (Hettmann et al., 1998; Dopson et al., 2005; Auernik and Kelly, 2008) bacteria. The most promising efforts to date have focused on the iron respiratory chain of Acidithiobacillus ferrooxidans, where an iron "respirasome" super complex has been defined that is comprised of $2 c$-type cytochromes, a blue copper protein called rusticyanin, and an $a a_{3}$-type terminal oxidase (Castelle et al., 2008). The proteins in the aerobic iron respiratory pathway of At. ferrooxidans do not appear to be expressed in many of the phylogenetically distinct bacteria that also respire on iron. Similarly, redox-active proteins expressed in other iron-grown bacteria do not appear to be expressed in iron-grown At. ferrooxidans. Comparative analyses conducted using those relevant bacterial genomes where partial or complete DNA sequence data is available 
(Chen et al., 2005; Ram et al., 2005; Valdes et al., 2008; Clum et al., 2009; Siezen and Wilson, 2009) have not yet provided significant insight into other iron respiratory proteins or pathways. There is little information in the DNA databases to compare with because the proteins in the aerobic iron respiratory pathway of At. ferrooxidans do not appear to be universal among those bacteria that respire on iron. In either case, actual respiratory electron transfer in the intact organism is not directly observed. Rather, the functional properties of the intact electron transfer chain are inferred from observations on isolated molecules.

This paper introduces a new means to study respiratory electron transfer reactions in situ in intact bacteria under physiological conditions. The premise is that accurate UV-visible spectroscopy of electron transfer reactions among colored cytochromes can be conducted in highly turbid suspensions if the live bacteria are irradiated in an isotropic homogeneous field of incident measuring light. Under those conditions, the absorbed radiant power is independent of scattering effects (Elterman, 1970; Fry et al., 1992; Javorfi et al., 2006; Hodgkinson et al., 2009). We conducted equilibrium and kinetic studies on the $\mathrm{Fe}(\mathrm{II})$-dependent reduction and $\mathrm{O}_{2}$-dependent oxidation of cytochromes in intact Leptospirillum ferrooxidans at $\mathrm{pH}$ 1.7. We used a commercial integrating cavity absorption meter (ICAM) where the cuvette comprised a reflecting cavity completely filled with the absorbing suspension. $L$. ferrooxidans was selected because it is only known to respire on one substrate, reduced iron (Harrison, 1984). We observed that a cytochrome with a reduced spectral peak at $579 \mathrm{~nm}$ is an obligatory intermediate in the aerobic iron respiratory chain of $L$. ferrooxidans.

\section{MATERIALS AND METHODS CELL CULTURE}

Leptospirillum ferrooxidans DSMZ 2705 was cultured autotrophically on soluble ferrous ions at $30^{\circ} \mathrm{C}$ in the medium described elsewhere (Tuovinen and Kelly, 1973), adjusted to $\mathrm{pH} 1.5$ and amended with $44 \mathrm{~g} / \mathrm{l}$ of $\mathrm{FeSO}_{4} \cdot 7 \mathrm{H}_{2} \mathrm{O}$. Cells grown to stationary phase were harvested by centrifugation, washed three times with $0.02 \mathrm{M} \mathrm{H}_{2} \mathrm{SO}_{4}, \mathrm{pH} 1.7$, and resuspended in sufficient $0.02 \mathrm{M}$ $\mathrm{H}_{2} \mathrm{SO}_{4}$ to achieve a stock suspension of $1.5 \times 10^{10} \mathrm{cells} / \mathrm{ml}$. The stock suspension was stored at $4^{\circ} \mathrm{C}$ for up to 2 weeks while spectroscopic experiments were conducted on aliquots of the cells. Previous stock suspensions of this organism have been stored in dilute sulfuric acid at $4^{\circ} \mathrm{C}$ for over 6 weeks before changes in the bacterium's energy metabolism could be detected.

\section{QUANTIFICATION OF BACTERIA}

Absolute numbers of $L$. ferrooxidans cells were determined by electrical impedance measurements in a Multisizer 4 particle counter (Beckman Coulter, Inc., Brea, CA, USA) fitted with a $30-\mu \mathrm{m}$ aperture. The instrument was programmed to siphon $50 \mu l$ of sample that contained Isoton II as the electrolyte. The current applied across the aperture was $600 \mu \mathrm{A}$. Voltage pulses attendant with impedance changes as particles passed through the aperture were monitored with an instrument gain of four.

Relative numbers of $L$. ferrooxidans cells were determined by photon correlation scattering spectroscopy with a DelsaNano C particle size analyzer, also from Beckman Coulter, Inc. Cell densities were adjusted to $8.3 \times 10^{6}$ cells $/ \mathrm{ml}$ in $0.02 \mathrm{M}$ sulfuric acid to give an attenuator obscuration of $47 \%$. Determination of the relative numbers of light scattering species as a function of particle diameter was accomplished by the time domain method with operating and analysis software provided by Beckman Coulter, Inc.

\section{ABSORBANCE MEASUREMENTS WITH CELL SUSPENSIONS}

Absorbance measurements on intact cells in suspension were conducted in an Olis CLARiTY 1000 A spectrophotometer (On Line Instrument Systems, Inc., Bogart, GA, USA) that employed a novel ICAM. In a typical experiment, identical $4.2 \mathrm{ml}$ solutions that contained ferrous sulfate in $0.02 \mathrm{M}$ sulfuric acid, $\mathrm{pH} 1.7$, were added to both the sample and reference observation cavities of the spectrophotometer. After recording a stable baseline from 350 to $650 \mathrm{~nm}, 140 \mu \mathrm{l}$ were withdrawn from the sample cavity and replaced with $140 \mu \mathrm{l}$ of the stock cell suspension of $L$. ferrooxidans. Apparent absorbance spectra (typically $6.2 \mathrm{~s}^{-1}$ ) were then collected until any visible absorbance changes had ceased. Raw apparent absorbance values were converted to absorbance values per cm using Fry's method (Fry et al., 2010) as described in the text.

\section{RESULTS \\ THE REDOX STATE OF ELECTRON TRANSFER PROTEINS CAN BE MONITORED IN SITU IN INTACT BACTERIA UNDER PHYSIOLOGICAL CONDITIONS}

The principal features of the novel CLARiTY spectrophotometer used to conduct absorbance measurements in turbid solutions are included in the schematic diagram shown in Figure 1. The sample and reference observation cells of this dual beam spectrophotometer were each comprised of a $4.2-\mathrm{ml}$ spherical quartz cuvette fused with a 6-mm ID quartz tube. Each quartz chamber was surrounded by a tightly packed proprietary white powder that served to maximize diffuse reflectance of light on the exterior walls of the spherical flask. The apertures in the reflecting sphere through which the measuring light entered and the transmitted/scattered light exited to the photomultiplier tube were positioned at a $90^{\circ}$ angle such that the light had to undergo many reflections and cell transversals before it was quantified using the photomultiplier tube. A white Teflon plug with a 6-mm OD was inserted into the quartz tube to minimize the loss of light out of the neck. A 1.0$\mathrm{cm}$ white stir bar was included in the sample chamber to facilitate sample mixing and suspension of any particulate matter.

The data shown in Figure 2 illustrate how the intact cells of $L$. ferrooxidans were quantified. The solid line in Figure 2 shows the absolute counts as a function of particle size as determined with a suspension of $L$. ferrooxidans in the Multisizer 4. The Multisizer determined the number and size of intact bacteria suspended in an electrically conductive liquid by forcing a measured volume of the suspension to flow through a small aperture with an immersed electrode on either side. A current passing through the aperture between the two electrodes enabled the bacteria to be detected by the momentary changes in the electrical impedance as they passed through the aperture, since each bacterium displaced its own volume of electrolyte solution within the aperture itself. These changes in impedance were detected as a series of voltage pulses, for which the height and duration of each pulse were proportional to the volume of the bacterium that produced 
it. Each pulse was counted and allocated to 1 of 400 arbitrary size categories, or channels. Each channel encompassed a narrow range of volumes that were converted to spherical equivalents and represented by the corresponding spherical diameters on the abscissa of Figure 2. The solid line in Figure 2 shows the number of counts in each size range for spherical equivalents with diameters from 0.6 to $2.0 \mu \mathrm{m}$.

The dashed line in Figure 2 shows the relative number of $L$. ferrooxidans cells as a function of particle size as determined by laser light diffraction. Light scattered by the bacterial suspension produced a diffraction pattern from which the relative numbers of the scattering species at each particle size were calculated. Like the Multisizer, the particle sizes determined by laser light diffraction are expressed as spherical equivalents and are also represented by the corresponding spherical diameters on the abscissa of Figure 2.

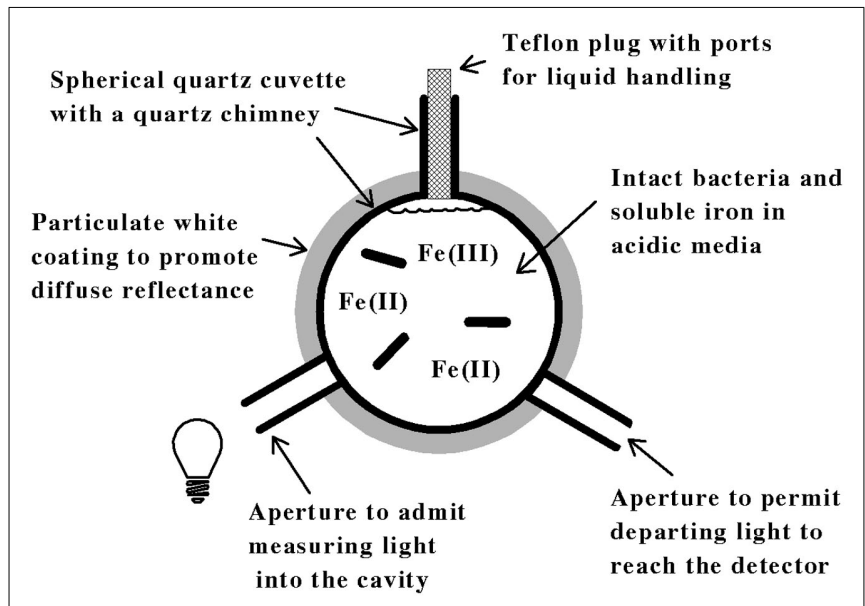

FIGURE 1 | Simplified model of an integrating cavity absorption meter designed to permit accurate absorbance measurements in media that scatter light.

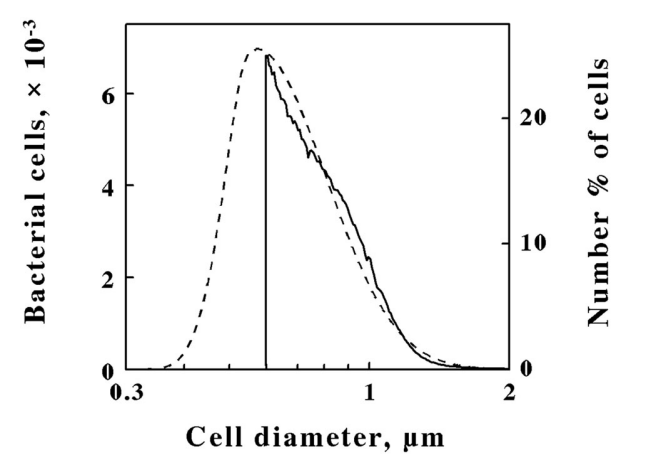

FIGURE 2 | Comparison of $L$. ferrooxidans cell populations by electrical impedance (solid line) and static light diffraction methods (dashed line). Electrical impedance measurements yielded absolute numbers of cells (left ordinate) as a function of size; light diffraction measurements yielded relative numbers of cells (right ordinate) as a function of size. The scale of each ordinate was chosen to facilitate comparison of the curves. The area under the electrical impedance curve was $81.2 \%$ of that under the light diffraction curve.
Close correspondence between the electrical impedance and the light diffraction curves was observed down to $0.6 \mu \mathrm{m}$, indicating that the two instruments were monitoring the same population of particles. Bacteria with effective diameters less than $0.6 \mu \mathrm{m}$ were underrepresented by the electrical impedance method, by which observations were limited to particles with effective diameters between 2 and $60 \%$ of the $30-\mu \mathrm{m}$ aperture employed, while the light diffraction method was capable of resolving particles with effective diameters smaller than $0.1 \mu \mathrm{m}$. On the basis of comparisons such as that illustrated in Figure 2, it was determined that $19.8 \%$ of the bacterial cell counts were below the limit of resolution of the electrical impedance method with the $30-\mu \mathrm{m}$ aperture. Accordingly, absolute counts of L. ferrooxidans cells obtained by the electrical impedance method were multiplied by 1.23 to correct for the percentage of bacterial counts that were below the limit of resolution of the instrument.

Cell pellets of L. ferrooxidans, which were a pinkish tan color, were obtained by centrifugation of batch cultures grown to stationary phase on soluble ferrous iron. Curve a in Figure 3 shows the absorbance spectrum of oxidized L. ferrooxidans that was obtained in the CLARiTY spectrophotometer in sulfuric acid, $\mathrm{pH}$ 1.7. Even though the cell suspension contained $5 \times 10^{8}$ cells $/ \mathrm{ml}$ and was roughly as turbid as non-fat milk, the resulting absorbance spectrum contained no evidence of the light scattering artifacts that one would observe by conducting the same absorbance measurements using a conventional linear spectrophotometer. The spectrum in curve a showed a clearly defined Soret peak at $422 \mathrm{~nm}$ and a broad $\alpha, \beta$ band at around $520 \mathrm{~nm}$.

The goal of the initial spectroscopic experiments was simply to determine whether the pink protein(s) in the cells changed color when the cells were suspended in sulfuric acid and subsequently exposed to excess concentrations of soluble ferrous ions under physiological conditions. Curve $\mathbf{b}$ in Figure $\mathbf{3}$ shows the absorbance spectrum that was obtained when the cells of oxidized L. ferrooxidans were exposed to $100 \mathrm{mM}$ ferrous sulfate in sulfuric acid, $\mathrm{pH}$ 1.7. Exposure to excess soluble iron caused the apparent

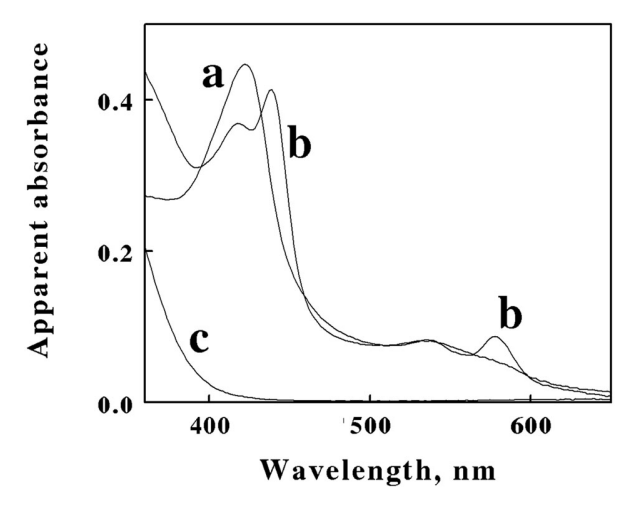

FIGURE 3 | Apparent absorbance spectra of intact $L$. ferrooxidans collected in the CLARiTY in the absence $(a)$ and presence $(b)$ of $100 \mathrm{mM}$ ferrous sulfate in aerobic sulfuric acid, $\mathbf{p H}$ 1.7. The final bacterial suspension contained $2.1 \times 10^{9}$ cells of $L$. ferrooxidans in $4.2 \mathrm{ml}$. Curve $c$ shows the apparent absorbance spectrum of $50 \mu \mathrm{M}$ ferric ions under the same solution conditions in the absence of bacteria. 
Soret peak to split into two peaks with maxima at 418 and $439 \mathrm{~nm}$. In addition, a new absorbance peak appeared with a maximum absorbance at $579 \mathrm{~nm}$. The absorbance spectrum represented by curve $\mathbf{b}$ appeared immediately after mixing the bacterial suspension in the observation cell that contained the $100-\mathrm{mM}$ soluble iron $(\leq 0.5 \mathrm{~s})$. This observation indicated that the iron-dependent reduction of the cytochrome(s) in intact $L$. ferrooxidans was essentially complete within the 0.5 -s mixing time in the observation cell of the spectrophotometer. The resulting spectrum was very stable and did not vary for at least an hour after mixing. Although the live cells could respire aerobically on the soluble iron, the great molar excess of iron over molecular oxygen in the observation cell dictated that the cytochromes in the cells would remain predominantly reduced as the oxygen in the chamber was consumed. Evidence for aerobic respiration was taken from the increase in absorbance at wavelengths below $400 \mathrm{~nm}$ in curve b. Curve $\mathbf{c}$ in Figure 3 shows the absorbance spectrum of $50 \mu \mathrm{M}$ ferric sulfate in sulfuric acid, $\mathrm{pH}$ 1.7. The increase in the absorbance observed at low wavelengths in curve $\mathbf{b}$ was assumed to be due to ferric ions produced as a consequence of aerobic respiration on iron by the bacteria.

The goal of subsequent spectroscopic experiments was to lower the concentration of soluble iron and determine whether time-dependent changes in the cellular absorbance could be detected. Fe(II) concentrations were chosen such that the total number of electrons available for aerobic respiration was lower than the electron-accepting capacity of the $>200 \mu \mathrm{M} \mathrm{O}_{2}$ in the air-saturated suspension. The data in Figure 4A show selected absorbance spectra that were obtained when cells of $L$. ferrooxidans were exposed to $100 \mu \mathrm{M}$ ferrous sulfate in sulfuric acid, $\mathrm{pH}$ 1.7. The seven absorbance spectra shown in the figure were selected from a data set where 6.2 complete scans from 350 to $650 \mathrm{~nm}$ were collected every second for $400 \mathrm{~s}$. Once again, the spectrum of the bacteria produced in the presence of $\mathrm{Fe}(\mathrm{II})$ was generated within the operational dead time of mixing, roughly $0.5 \mathrm{~s}$. In this case, however, subsequent aerobic respiration under the conditions of excess molecular oxygen produced time-dependent changes in the observed spectra of whole cells. The reduced peaks at 439 and $579 \mathrm{~nm}$ disappeared over a period of $400 \mathrm{~s}$, while the oxidized Soret peak at $422 \mathrm{~nm}$ gradually reappeared. In addition, there was a concomitant increase in absorbance at wavelengths below $400 \mathrm{~nm}$. These spectral changes were consistent with the hypothesis that the cells respired aerobically on the soluble iron until the ferrous iron was completely oxidized.

The primary absorbance spectra shown in Figures 3 and $\mathbf{4 A}$ are presented as "apparent absorbance" because of prior reports that spectra obtained using integrated cavity absorption meters appear distorted when compared with corresponding spectra of the same
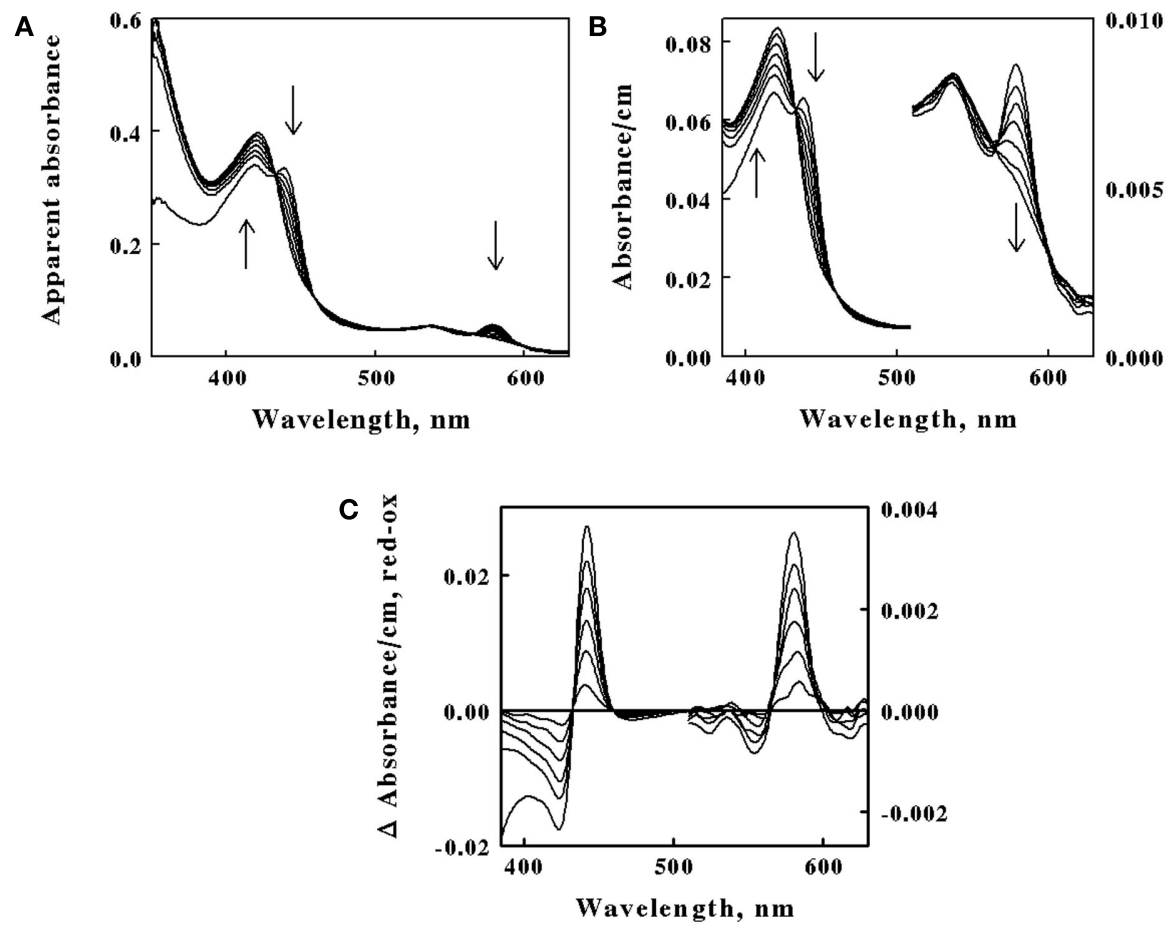

FIGURE 4 | Absorbance spectra obtained at different time points after $2.1 \times 10^{9}$ cells of intact $L$. ferrooxidans were introduced into $4.2 \mathrm{ml}$ of $\mathbf{1 0 0} \mu \mathbf{M}$ ferrous sulfate in sulfuric acid, $\mathbf{p H}$ 1.7. (A) Apparent absorbance spectra collected in the CLARiTY at seven time points after mixing, ranging from 1.0 to $400 \mathrm{~s}$. Each arrow indicates whether the apparent absorbance at that wavelength increased or decreased with time. (B) Absorbance spectra obtained when the apparent absorbance values in (A) were converted to equivalent absorbance values per $\mathrm{cm}$ using the Fry equation (see text) to adjust for mean path length differences at different wavelengths. The absorbances at the longer wavelengths correspond to the more sensitive scale shown on the right ordinate. (C) Difference spectra, representing the absolute spectrum of the iron-reduced $L$. ferrooxidans minus those obtained at selected time points following the initial reduction of the bacteria. 
materials obtained using a conventional linear spectrophotometer (Elterman, 1970; Fry et al., 1992; Javorfi et al., 2006; Hodgkinson et al., 2009). Unlike single path length spectrophotometers where the Beer-Lambert law governs non-linearity in the measured light intensity as a function of analyte concentration, the measuring light in an integrating sphere makes multiple random passes with different path lengths that exacerbate the apparent non-linearity with analyte concentration. While others have used semi-empirical methods to provide distortion-free spectra (Javorfi et al., 2006), we utilized the approach suggested by Fry because it is based on derivations from first principles (Fry et al., 1992, 2010). Fry arrived at the following exact expression for fractional absorption in an ICAM:

$1-T=\frac{1-\exp \left[-\alpha(\nu) L_{\mathrm{G}}\right]}{1-\rho(1-h) \exp \left[-\alpha(\nu) L_{\mathrm{G}}\right]}$

where $\mathrm{T}$ equals the observed transmittance in the ICAM, $\alpha(v)$ equals the corresponding absorbance that would be observed in a single path length spectrophotometer, $L_{\mathrm{G}}$ represents the mean geometric path length which for a sphere equals $2 / 3$ of the sphere's diameter, $\rho$ represents the reflectance at the walls of the cavity and is a number between 0 and 1 , and $h$ is the fraction of the cavity wall that is open for ports. Equation 1 was rearranged to

$\alpha(v)=-\ln \left[\frac{10^{-A}}{1-\rho(1-h)\left(1-10^{-A}\right)}\right] / L_{\mathrm{G}}$

where $A$ is the absorbance value observed in the CLARiTY and $\rho(1-h)$ was determined in separate experiments to be equal to 0.92 (data not shown).

The spectra shown in Figure 4B were obtained when the absorbance values in Figure 4A were converted to equivalent absorbance values per $\mathrm{cm}$ using Eq. 2. The converted absorbance values in Figure 4B illustrate the enhanced sensitivity achieved in the CLARiTY where the mean path length of the measuring light is increased by multiple reflections around the interior of the cavity. The conversion also eliminated the apparent distortion in the raw absorbance values wherein the Soret peak appeared to be attenuated compared to the heme absorbance at longer wavelengths. Thus those wavelengths where greater absorption occurred received relatively higher values in the converted data than did those wavelengths where lower absorption occurred.

Figure 4C shows difference spectra representing the absolute absorbance spectrum of the iron-reduced L. ferrooxidans minus those obtained at various time points following the rapid reduction of the bacteria. The two prominent peaks of the difference spectrum occur at 443 and $579 \mathrm{~nm}$. The observation of at least four relatively well-defined isosbestic points is extraordinary considering that the spectra were acquired in a highly turbid suspension of bacteria. An isosbestic point is a specific wavelength at which two or more absorbing species have the same molar absorptivity. The existence of those four well-defined isosbestic points suggests that there is only one principal iron-responsive cytochrome that is visible in the aerobic iron respiratory chain of $L$. ferrooxidans.

\section{REDUCED CYTOCHROME 579 IS AN OBLIGATORY INTERMEDIATE DURING AEROBIC RESPIRATION ON SOLUBLE IRON BY INTACT L. FERROOXIDANS}

The next goal was to determine whether the time-dependent absorbance changes observed when intact $L$. ferrooxidans was exposed to soluble ferrous ions could be correlated with the appearance of product ferric ions as the bacterium respired aerobically on reduced iron. The kinetic data shown in Figure 5A were extracted from the data set that yielded the selected spectra shown in Figure 4A. The change in absorbance at $355 \mathrm{~nm}$, which represented predominantly the absorbance due to the time-dependent accumulation of ferric ions, increased in a roughly linear fashion until the limiting concentration of ferrous ions was completely depleted at around $320 \mathrm{~s}$ after the start of the bacterial-catalyzed reaction. The changes in absorbance at $443 \mathrm{~nm}$, which represented the peak of the difference spectrum in the Soret region shown in Figure 4C, slowly decreased over the time course of the reaction until about $300 \mathrm{~s}$, when the absorbance then decreased rapidly back to the initial absorbance observed in the bacterium under airoxidized conditions. It was evident that the cellular cytochrome returned to the oxidized state at about the same time that the product formation ceased.

The close correspondence between the change in product formation and the transient changes in the redox state of cytochrome 579 in intact $L$. ferrooxidans was consistent with the minimal kinetic mechanism shown in Figure 5B. Briefly, the irondependent reduction of cytochrome 579 in the intact bacterium is depicted as a relatively rapid reaction, which is consistent with the observation that it is complete within the 0.5 -s dead time of the mixing even when the concentration of soluble ferrous ions is only $100 \mu \mathrm{M}$. The bacterium with its reduced cellular cytochrome is then shown as reacting with molecular oxygen to regenerate oxidized cytochrome/bacterium in a slower reaction that constitutes the rate-limiting catalytic step. The exchange of electrons between the bacterium and soluble iron is depicted as a reversible reaction until or if experimental observations indicate otherwise.

The kinetic mechanism shown in Figure 5B is readily modeled by the Michaelis-Menten formalism where the intact bacterium that contains the reduced cytochrome 579 represents the Michaelis complex. It follows that the velocity of product formation should be a hyperbolic function of the concentration of the substrate ferrous ions, as shown below:

$-\frac{\mathrm{d}[\mathrm{Fe}(\mathrm{II})]}{\mathrm{dt}}=\frac{\mathrm{d}[\mathrm{Fe}(\mathrm{III})]}{\mathrm{dt}}=\frac{V_{\max }[\mathrm{Fe}(\mathrm{II})]}{K_{\mathrm{M}}+[\mathrm{Fe}(\mathrm{II})]}$

where $V_{\max }$ is the maximum velocity of the bacterial-catalyzed aerobic oxidation of ferrous ions and $K_{\mathrm{M}}$ is the Michaelis constant for soluble iron. Figure 5C shows the dependence of the velocity of the absorbance changes at $355 \mathrm{~nm}$ on the concentration of ferrous ions that remained in solution when intact cells were mixed with $100 \mu \mathrm{M}$ ferrous ions. The data points in Figure 5C represent the tangents to the 355-nm curve in Figure 5A that correspond to the same time points as those at the different concentrations of ferrous ion shown on the abscissa of Figure 5C. The values for the rectangular hyperbola drawn through the data points in Figure 5C 


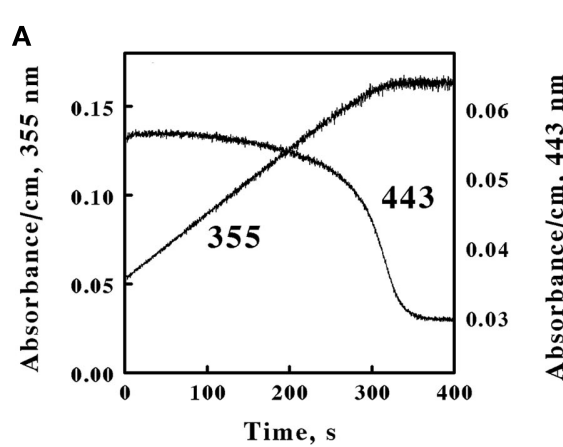

B

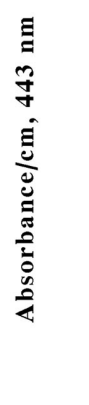

C

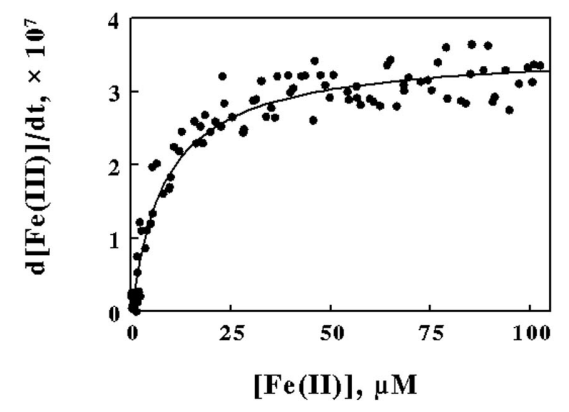

FIGURE 5 | The absorbance of the reduced cytochrome in intact $L$. ferrooxidans correlates with the absorbance of ferric ions produced during aerobic respiration on soluble iron. (A) Time courses of the absorbance changes at 355 and $443 \mathrm{~nm}$ obtained when $2.1 \times 10^{9}$ cells of $L$. ferrooxidans were mixed with $100 \mu \mathrm{M}$ ferrous sulfate in sulfuric acid, pH 1.7. (B) Schematic representation of the kinetic mechanism for aerobic respiration on soluble iron as catalyzed by intact $L$. ferrooxidans.

were derived from a non-linear least-squares fit of Eq. 3 to the data with an apparent $V_{\max }$ of $3.6 \times 10^{-7} \mathrm{Ms}^{-1}$ and a $K_{\mathrm{M}}$ of $8.7 \mu \mathrm{M}$.

Another prediction that follows from the application of the Michaelis-Menten formalism to the kinetic mechanism shown in Figure 5B is that the rate of appearance of ferric ions should be directly proportional to the concentration of the reduced cytochrome 579 as shown in Eq. 4:

$-\frac{\mathrm{d}[\mathrm{Fe}(\mathrm{II})]}{\mathrm{dt}}=\frac{\mathrm{d}[\mathrm{Fe}(\mathrm{III})]}{\mathrm{dt}}=k_{\mathrm{cat}}[$ reduced cytochrome 579$]$

Figure 5D shows the dependence of the velocity of the absorbance changes at $355 \mathrm{~nm}$ on the concentration of reduced cytochrome 579. The velocities, or tangents to the 355-nm curve in Figure 5A, are the same values as those used in Figure 5C. In Figure 5D, the relative concentrations of reduced cytochrome 579 are represented on the abscissa by the differences in absorbance between those observed at $443 \mathrm{~nm}$ at corresponding time points in Figure 5A minus the stable absorbance observed at $443 \mathrm{~nm}$ at the end of the reaction. The direct proportionality predicted by Eq. 4 is evident, and the slope of the least-squares line in Figure 5D yielded a value for $k_{\text {cat }}$ of $1.4 \mathrm{~s}^{-1}$.

A third prediction that follows from the application of the Michaelis-Menten formalism to the kinetic mechanism shown in Figure 5B is shown in Figure 6. Equation 4 may be integrated to

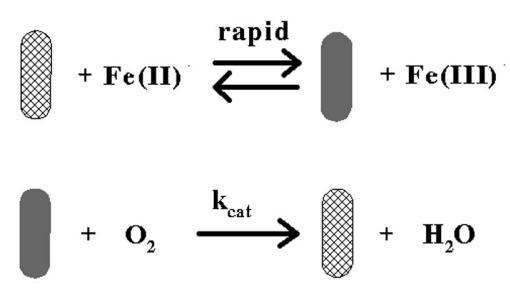

D

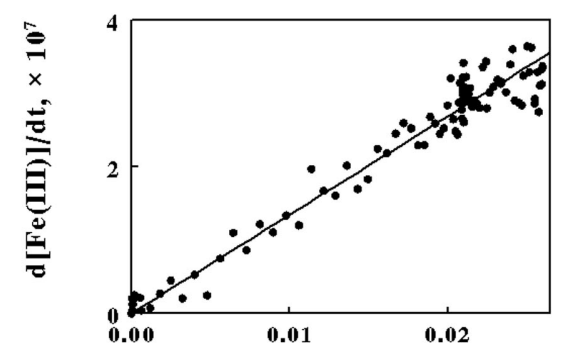

$\Delta$ Absorbance $443 \mathrm{~nm} / \mathrm{cm}$, red-ox

The cross-hatched and solid rods represent bacteria that contain oxidized and iron-reduced cytochromes, respectively. (C) Dependence of the velocity of the absorbance change at $355 \mathrm{~nm}$ on the concentration of ferrous ions that remain in solution. (D) Dependence of the velocity of the absorbance changes at $355 \mathrm{~nm}$ on the difference in absorbance values at $443 \mathrm{~nm}$, representing the value at $1.0 \mathrm{~s}$ minus the value at time $t$.

yield the following:

$[\mathrm{Fe}(\mathrm{II})]_{\text {Total }}=k_{\mathrm{cat}} \int[$ reduced cytochrome 579$] \mathrm{dt}$

where the integral on the right side of the equality represents the total area swept out by the absorbance of the reduced cytochrome over time as illustrated by the $443-\mathrm{nm}$ time course shown in Figure 5A. The kinetic curves in Figure 6A show the time courses of the absorbance changes at $443 \mathrm{~nm}$ that were obtained when constant concentrations of $L$. ferrooxidans were mixed with different total concentrations of ferrous ions from 25 to $125 \mu \mathrm{M}$. Although the duplicate curves in Figure 6A appeared to differ slightly, the total areas under each pair of curves were remarkably similar, as shown by the five pairs of closely matched data points in Figure 6B. The direct proportionality predicted by Eq. 5 is evident, and the slope of the least-squares line in Figure 6B yielded a value for $k_{\text {cat }}$ of $1.3 \mathrm{~s}^{-1}$.

\section{DISCUSSION}

Three things can happen to the measuring light in a conventional linear spectrophotometer equipped with a standard 1-cm cuvette: it can be transmitted; it can be absorbed; or it can be scattered without absorption. When the sample is not optically clear, the apparent attenuation of the measuring light reflects losses due 


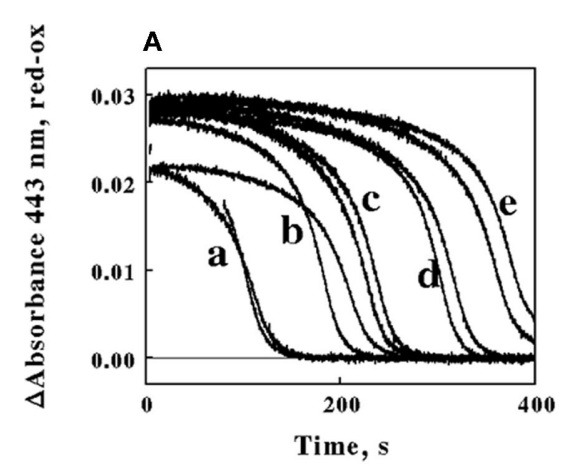

FIGURE 6 |The time integral of the absorbance of the reduced cytochrome in intact $L$. ferrooxidans correlates with the initial concentration of ferrous ions in the solution. (A) Time courses of the differences in the absorbance changes at $443 \mathrm{~nm}$ on the initial concentration of ferrous ions. Cells of $L$. ferrooxidans $\left(2.1 \times 10^{9}\right)$ were

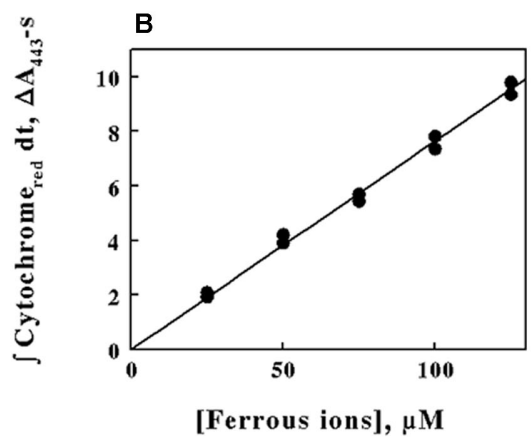

introduced into sulfuric acid, $\mathrm{pH} 1.7$, that contained 25,50,75, 100, and $125 \mu \mathrm{M}$ ferrous sulfate in curves a through $e$, respectively; each curve was obtained in duplicate. (B) Dependence of the area swept out under the absorbance versus time curves in (A) on the initial concentrations of ferrous ions. both to true molecular absorption and light lost to scattering by the particulate matter in the turbid suspension (Shibata et al., 1954; Merzlyak and Naqvi, 2000). Efforts to recover and quantify the scattered light have included placing the cuvette inside an integrating sphere with a reflective surface (Nelson and Prezelin, 1993) and positioning the cuvette outside the sphere (Merzlyak and Naqvi, 2000). In either case data interpretation required cumbersome and arcane methods to identify and separate the scattered light from the truly absorbed light. Other investigators have described ICAMs where a spherical cavity created and bounded by a reflective surface was completely filled with the absorbing material (Elterman, 1970; Fry et al., 1992; Javorfi et al., 2006; Hodgkinson et al., 2009). The principle behind the ICAM is that the apparent absorbance recorded by the photodetector will be independent of scattering effects if the sample is in an isotropic homogeneous field of light, like that provided by illuminating the interior of an ICAM surrounded by a surface that maximizes diffuse reflectance. The commercial integrating spectrophotometer utilized herein was loosely based on those described by others (Elterman, 1970; Fry et al., 1992; Javorfi et al., 2006; Hodgkinson et al., 2009) with two notable improvements: it was a dual beam instrument with both sample and reference compartments equipped with matching ICAMs; and it permitted the rapid acquisition of up to 100 absorbance scans per second over a wavelength range of $300 \mathrm{~nm}$. Another notable feature of this and all other ICAMs is that the effective path length of the observation chamber must be considerably longer than the diameter of the cavity due to multiple reflections at the cavity wall, a feature that provides much greater sensitivity.

Prior reductionist studies reported that cell-free extracts derived from iron-grown L. ferrooxidans (Hart et al., 1991; Blake and Shute, 1997), the closely related L. ferriphilum (Ram et al., 2005), or a microbial community with a low diversity of microbes that was dominated by Leptospirillum group II bacteria (Singer et al., 2008) all contained readily discernible quantities of an acid-soluble, acid-stable cytochrome with an unusual absorbance maximum at $579 \mathrm{~nm}$ in the reduced state. The probable participation of this novel cytochrome 579 in the aerobic iron respiratory chain of the Leptospirillum species is implied because the only known reducing substrates for aerobic respiration that are utilized by these organisms are soluble and insoluble ferrous iron. The same logic applies to the observations that the gene product of the DNA that encodes for cytochrome 579 was expressed in the microbial communities dominated by Leptospirillum group II bacteria. In either case, the participation of the expressed cytochrome was inferred from its existence and its cell-free behavior, but no direct observations of its function in situ were reported.

It is very difficult to reconstitute functional electron transport chains using partially purified components from cell-free extracts when the organism is an obligate acidophile like L. ferrooxidans. If the cell-free extracts are prepared at strongly acidic $\mathrm{pH}$ values, one must be concerned about altering or even precipitating those terminal components of the chain that face inward toward the cytoplasm, which is generally agreed to be neutral or only mildly acidic at the worst (Cobley and Cox, 1983; Michels and Bakker, 1985). If the cell-free extracts are prepared at near neutral $\mathrm{pH}$ values, one must be concerned about altering the functional behavior of those initial components of the chain that normally exchange electrons in their strongly acidic milieu. In addition, ionic iron is not sufficiently soluble at near neutral $\mathrm{pH}$ to permit functional studies on ferrous reduction of purified proteins or components within cell-free extracts. The surest way to study the details and principal features of respiratory electron transfer in obligate acidophiles is to conduct direct observations on the intact chain as it functions in situ under physiological conditions. That type of direct observation now appears to be possible using the ICAM that effectively negates the effects of light scattering by the turbid suspensions of intact bacteria.

Any kinetic mechanism that is described by the MichaelisMenten formalism generates at least three hypotheses (Chance, 1943; Bright and Porter, 1975): (i) the velocity of product formation must be a hyperbolic function of the substrate concentration; (ii) the velocity of product formation must be directly proportional to the concentration of the catalyst-substrate complex from which product formation occurs in a rate-limiting reaction; and (iii) the total amount of product formed (or substrate utilized) must be directly proportional to the integral 
over time of the concentration of the limiting catalyst complex. The behavior of the intact L. ferrooxidans and its reduced cytochrome 579 fulfilled the predictions of all three hypotheses. The $V_{\max }$ obtained from the non-linear fit of Eq. 3 to the data in Figure $5 \mathrm{C}$ was $3.6 \times 10^{-7} \mathrm{~mol}$ of iron oxidized/s/liter. This rate equals $2.6 \times 10^{-15} \mathrm{~mol}$ of iron oxidized/hour/cell, because there were $5 \times 10^{8}$ cells $/ \mathrm{ml}$ in the observation cavity. If one assumes that there are roughly $6 \times 10^{-14} \mathrm{~g}$ of carbon per cell of $L$. ferrooxidans (Blake et al., 1994), then the maximum rate of iron oxidation becomes approximately $0.5 \mathrm{~mol}$ of iron oxidized/hour/mole of cellular carbon. This value is slightly lower than those reported elsewhere for L. ferrooxidans at temperatures from 30 to $40^{\circ} \mathrm{C}$ and slightly different $\mathrm{pH}$ values (Eccleston et al., 1985). Similarly, the value of $K_{\mathrm{M}}$ of $8.7 \mu \mathrm{M}$ that was derived from the data in Figure 5C is quite a bit lower than those ranging from 250 to $500 \mu \mathrm{M}$ as reported by others for the same strain of $L$. ferrooxidans (Eccleston et al., 1985). The origins of these differences are unknown.

It must be noted that direct observations on electron transport reactions in intact bacteria also have their limitations if one or more of the colored components has a small absorption coefficient or is present in considerably lower concentrations than those of the other components. The studies described above offer a case in point. If cytochrome 579 participates in the aerobic iron respiratory chain of $L$. ferrooxidans, then what are the other components and why are they not equally prominent in the visible absorbance spectra collected using the intact bacteria? The remarkably clear isosbestic points observed in Figures 4B,C indicate that cytochrome 579 is by far and away the principal absorbing species that undergoes changes in its redox state during the reaction. Given the extreme acid stability of the cytochrome 579 that was purified from cell-free extracts of $L$. ferriphilum (Ram et al., 2005), one can hypothesize that the cytochrome 579 functions outside of the plasma membrane and is perhaps the initial cellular electron acceptor from ferrous ions in the acidic milieu. It is unlikely that a single acid-stable, acid-soluble cytochrome is both the initial iron oxidase in the acid milieu and the terminal oxidase that reduces molecular oxygen. There must be subsequent electron transfer reactions across the plasma membrane to one or more components on the cytosolic side to be consistent with the Mitchell hypothesis as it is applied to oxidative phosphorylation in obligate acidophiles (Ingledew, 1982). Perhaps these putative components either possess lower absorption coefficients or they are present at much lower concentrations than the prominent cytochrome 579. In addition to the exergonic transfer of electrons from $\mathrm{Fe}$ (II) to molecular oxygen, L. ferrooxidans must also accomplish the "uphill" transfer of electrons from $\mathrm{Fe}(\mathrm{II})$ to $\mathrm{NAD}^{+}$or $\mathrm{NADP}^{+}$.

\section{REFERENCES}

Auernik, K. S., and Kelly, R. M. (2008). Identification of components of electron transport chains in the extremely thermoacidophilic crenarchaeon Metallosphaera sedula through iron and sulfur compound oxidation transcriptomes. Appl. Environ. Microbiol. 74, 7723-7732.

Blake, R. C. II, Howard, G. T., and McGinness, S. (1994). Enhanced yield of iron-oxidizing bacteria by

Presumably the formation of reduced pyridine dinucleotides for anabolic metabolism must also require electron transport proteins that, in principle, could be observed as they function in the intact bacterium. There were no indications of additional electron transport proteins in the spectra shown above.

Attempts to identify other electron transfer cytochromes in the aerobic iron respiratory chain of intact $L$. ferrooxidans using classical respiratory inhibitors were unsuccessful. Sodium cyanide complexes spontaneously with ferrous ions to form ferrocyanide (Blake et al., 1991). Similarly, when $100 \mu \mathrm{M}$ sodium azide was mixed with $1.0 \mathrm{mM}$ ferrous ions at $\mathrm{pH}$ 1.7, a new absorbance band with a peak at $380 \mathrm{~nm}$ formed rapidly and spontaneously in the spectrophotometer (data not shown). This spectrum was identical to that published previously for a aqueous complex of $\mathrm{Fe}(\mathrm{II})$ with azide (Chacarolli et al., 2000). Interestingly, when $100 \mu \mathrm{M}$ sodium azide was mixed with intact bacteria in the absence of Fe(II) at $\mathrm{pH}$ 1.7 , the cytochrome 579 was reduced to the same extent as that shown in Figure 3 or Figure 4 (data not shown). When L. ferrooxidans was heat-inactivated by incubating a suspension at $90^{\circ} \mathrm{C}$ for $30 \mathrm{~min}$, the cytochromes that were still visible in the intact cell did not show any change when exposed to $100 \mathrm{mM} \mathrm{Fe}$ (II).

Despite the limitations discussed above, the direct and accurate observation of absorbance changes in situ in intact organisms is a useful complement to traditional reductionist approaches and recent advances in proteomic and transcriptomic studies. The colored prosthetic groups of most electron transport proteins comprise intrinsic spectrophotometric probes whereby transient changes in the oxidation-reduction state of the proteins may be monitored with great sensitivity. There is no better means to establish physiological relevance in a metabolic function than to directly observe it as it occurs in the intact bacterium. The movement of electrons through electron transfer complexes is central to energy production in all living cells. The ability to conduct direct spectrophotometric studies under non-invasive physiological conditions represents a new and powerful approach to examine the extents and rates of biological events in situ without disrupting the complexity of the live cellular environment. Studies such as these should increase our fundamental understanding of biological energy transduction.

\section{ACKNOWLEDGMENTS}

This research was supported by grants DE-SC0007229 from the United States Department of Energy, 1G12RR026260 from the National Institutes of Health, and W911NF-07-1-001 from the United States Department of Defense through its Army Research Office.

Blake, R. C. II, Schute, E. A., Greenwood, M. M., Spencer, G. M., and Ingeldew, W. J. (1993). Enzymes of aerobic respiration on iron. FEMS Microbiol. Rev. 11, 9-18.

Blake, R. C. II, Schute, E. A., Waskovsky, J., and Harrison, A. P. Jr. (1992). Respiratory components in acidophilic bacteria that respire on iron. Geomicrobiol. J. 10, 173-192.
Blake, R. C. II, White, K. J., and Shute, E. A. (1991). Mixed ligand complexes of iron with cyanide and phenanthroline as new probes of metalloprotein electron transfer reactivity. $J$. Biol. Chem. 266, 19203-19211.

Bright, H. J., and Porter, D. J. T. (1975). "Flavoprotein oxidases," in The Enzymes XII: Oxidation Reduction Part B, ed. P. D. Boyer (New York, NY: Academic Press), 421-505. 
Castelle, C., Guiral, M., Malarte, G., Ledgham, F., Leroy, G., Brugna, M., and Giudici-Orticoni, M. T. (2008). A new iron-oxidizing/ $\mathrm{O}_{2}$ reducing supercomplex spanning both inner and outer membranes, isolated from the extreme acidophile Acidithiobacillus ferrooxidans. J. Biol. Chem. 283, 25803-25811.

Chacarolli, C. J., Andrade, J. F., Guimarales, O. M., Balbo, V. R., Venezuela, C. S., and Teruel, F. S. (2000). Spectrophotometric study of iron oxidation in the iron(II)/azide/tetrahyrofuran system and some analytical applications. Anal. Chim. Acta 411, 217-222.

Chance, B. (1943). The kinetics of the enzyme-substrate compound of peroxidase. J. Biol. Chem. 151, 553-577.

Chen, L., Brugger, K., Skovgaard, M, Redder, P., She, Q., Torarinsson, E., Greve, B., Awayez, M., Zibat, A., Klenk, H. P., and Garrett, R. A. (2005). The genome of Sulfolobus acidocaldarius, a model organism of the Crenarchaeota. J. Bacteriol. 187, 4992-4999.

Clark, D. A., and Norris, P. R. (1996). Acidimicrobium ferrooxidans gen. nov., sp. nov.: mixed-culture ferrous iron oxidation with Sulfobacillus species. Microbiology 142, 785-790.

Clum, A., Nolan, M., Lang, E., Del Rio, T. G., Tice, H., Copeland, A., Cheng, J. F., Lucas, S., Chen, F., Bruce, D., Goodwin, L., Pitluck, S., Ivanova, N., Mavromatis, K., Mikhailova, N., Pati, A., Chen, A., Palaniappan, K., Göker, M., Spring, S., Land, M., Hauser, L., Chang, Y. J., Jeffries, C. C., Chain, P., Bristow, J., Eisen, J. A., Markowitz, V., Hugenholtz, P., Kyrpides, N. C., Klenk, H. P., and Lapidus, A. (2009). Complete genome sequence of Acidimicrobium ferrooxidans type strain. Stand. Genomic Sci. 1, 38-45.

Cobley, J. G., and Cox, J. C. (1983). Energy conservation in acidophilic bacteria. Microbiol. Rev. 47, 579-595.

Cox, J. C., and Boxer, D. H. (1978). The purification and some properties of rusticyanin, a blue copper protein involved in iron (II) oxidation from Thiobacillus ferroxidans. Biochem. J. 174, 497-502.

Dinarieva, T. Y., Zhuravleva, A. E., Pavlenko, O. A., Tsaplina, I. A., and Netrusov, A. I. (2010). Ferrous iron oxidation in moderately thermophilic acidophile Sulfobacillus sibiricus N1T. Can. J. Microbiol. 56, 803-808.

Dopson, M., Baker-Austin, C., and Bond, P. L. (2005). Analysis of differential protein expression during growth states of Ferroplasma strains and insights into electron transport for iron oxidation. Microbiology 151 4127-4137.

Eccleston, M., Kelly, D. P., and Wood, A. P. (1985). "Autotrophic growth and iron oxidation and inhibition kinetics of Leptospirillum ferrooxidans," in Planetary Ecology, eds D. E. Caldwell, J. A. Brierley, and C. L. Brierley (New York, NY: Van Nostrand Reinhold), 263-272.

Elterman, P. (1970). Integrating cavity spectroscopy. Appl. Opt. 9, 2140-2142.

Fry, E. S., Kattawar, G. W., and Pope, R. M. (1992). Integrating cavity absorption meter. Appl. Opt. 31, 2055-2065.

Fry, E. S., Kattawar, G. W., Strycker, B. D., and Zhai, P. W. (2010). Equivalent path lengths in an integrating cavity: comment. Appl. Opt. 49, 575-577.

Golyshina, O. V., Pivovarova, T. A., Karavaiko, G. I., Kondrateva, T. F., Moore, E. R., Abraham, W. R., Lunsdorf, H., Timmis, K. N., Yakimov, M. M., and Golyshin, P. N. (2000). Ferroplasma acidiphilum gen. nov., sp. nov., an acidophilic, autotrophic, ferrous-iron-oxidizing, cell-wall-lacking, mesophilic member of the Ferroplasmaceae fam. nov., comprising a distinct lineage of the Archaea. Int. J. Syst. Evol. Microbiol. 50, 997-1006.

Golyshina, O. V., Yakimov, M. M., Lunsdorf, H., Ferrer, M., Nimtz, M., Timmis, K. N., Wray, V., Tindall, B. J., and Golyshin, P. N. (2009). Acidiplasma aeolicum gen. nov., sp. nov., a novel euryarchaeon of the family Ferroplasmaceae isolated from a hydrothermal pool, and transfer of Ferroplasma cupricumulans to Acidiplasma cupricumulans comb. nov. Int. J. Syst. Evol. Microbiol. 59, 2815-2823.

Guo, X., You, X. Y., Liu, L. J., Zhang, J. Y., Liu, S. J., and Jiang, C. Y. (2009). Alicyclobacillus aeris sp. nov., a novel ferrous iron- and sulfur-oxidizing bacterium isolated from a copper mine. Int. J. Syst. Evol. Microbiol. 59, 2415-2420.

Hallberg, K. B., Gonzalez-Toril, E., and Johnson, D. B. (2010). Acidithiobacillus ferrivorans, sp. nov.; facultatively anaerobic, psychrotolerant iron- and sulfur-oxidizing acidophiles isolated from metal mine-impacted environments. Extremophiles 14, 9-19.

Harrison, A. P. Jr. (1984). The acidic thiobacilli and other acidophilic bacteria that share their habitat. Annu. Rev. Microbiol. 38, 265-292.

Hart, A. J., Murrell, J. C., Poole, R. K., and Norris, P. R. (1991). An acid- stable cytochrome in iron-oxidizing Leptospirillum ferrooxidans. FEMS Microbiol. Lett. 81, 89-94.

Hettmann, T., Schmidt, C. L., Anemuller, S., Zahringer, U., Moll, H., Petersen, A., and Schafer, G. (1998). Cytochrome b558/566 from the archaeon Sulfolobus acidocaldarius. J. Biol. Chem. 273, 12032-12040.

Hodgkinson, J., Masiyano, D., and Tatam, R. P. (2009). Using integrating spheres as absorption cells: path-length distribution and application of Beer's law. Appl. Opt. 48, 5748-5758.

Huber, G., Spinnler, C., Gambacorta, A., and Stetter, K. O. (1989). Metallosphaera sedula gen. and sp. nov. represents a new genus of aerobic, metal-mobilizing, thermoacidophilic archaebacteria. Syst. Appl. Microbiol. 12, 38-47.

Huber, G., and Stetter, K. O. (1991). Sulfolobus metallicus, sp. nov., a novel strictly chemolithoautotrophic thermophilic archaeal species of metalmobilizers. Syst. Appl. Microbiol. 14, 372-378.

Huber, H., and Stetter, K. O. (1989). Thiobacillus prosperous sp. nov., represents a new group of halotolerant metal-mobilizing bacteria isolated from a marine geothermal field. Arch. Microbiol. 151, 479-485.

Ingledew, W. J. (1982). The bioenergetics of an acidophilic chemolithotroph. Biochim. Biophys. Acta 683, 89-117.

Javorfi, T., Erostyak, J., Gal, J., Buzady, A. Menczel, L., Grab, G., and Naqvi, K. R. (2006). Quantitative spectrophotometry using integrating cavities. J. Photochem. Photobiol. B Biol. 82, 127-131.

Jiang, C. Y., Liu, Y., Liu, Y. Y., You, X. Y., Guo, X., and Liu, S. J. (2009). Alicyclobacillus ferrooxydans sp. nov., a ferrous-oxidizing bacterium from solfataric soil. Int. J. Syst. Evol. Microbiol. 58, 2898-2903.

Johnson, D. B., Bacelar-Nicolau, P. Okibe, N., Thomas, A., and Hallberg, K. B. (2009). Ferrimicrobium acidiphilum gen. nov., sp. nov. and Ferrithrix thermotolerans gen. nov., sp. nov.: heterotrophic, ironoxidizing, extremely acidophilic actinobacteria. Int. J. Syst. Evol. Microbiol. 59, 1082-1089.

Johnson, D. B., Joulian, C., d'Hugues, P., and Hallberg, K. B. (2008). Sulfobacillus benefaciens sp. nov., an acidophilic facultative anaerobic Firmicute isolated from mineral bioleaching operations. Extremophiles 12, 789-798.
Karavaiko, G. I., Golyshina, O. V., Troitskii, A. V., Valieho-Roman, K. M., Golovacheva, R. S., and Pivovarova, T. A. (1994). Sulfurococcus yellowstonii sp. nov., a new species of iron- and sulfuroxidizing thermoacidophilic archaebacteria. Mikrobiologiya 63, 668-682.

Kelly, D. P., and Wood, A. P. (2000). Reclassification of some species of Thiobacillus to the newly designated genera Acidithiobacillus gen. nov., Halothiobacillus gen. nov. and Thermithiobacillus gen. nov. Int. J. Syst. Evol. Microbiol. 50, 511-516.

Markosyan, G. E. (1972). A new acidophilic iron bacterium Leptospirillum ferrooxidans. Biol. Zh. Arm. 25, 26-33.

Merzlyak, M. N., and Naqvi, K. R. (2000). On recording the true absorption spectrum and the scattering spectrum of a turbid sample: application to cell suspensions of the cyanobacterium Anabaena variabilis. J. Photochem. Photobiol. B Biol. 58, 123-129.

Michels, M., and Bakker, E. P. (1985). Generation of a large, protonophore-sensitive proton motive force and $\mathrm{pH}$ difference in the acidophilic bacteria Thermoplasma acidophilum and Bacillus acidocaldarius. J. Bacteriol. 161, 231-237.

Nelson, N. B., and Prezelin, B. B. (1993). Calibration of an integrating sphere for determining the absorption coefficient of scattering suspensions. Appl. Opt. 32, 6710-6717.

Norris, P. R., Clark, D. A., Owen, J. P., and Waterhouse, S. (1996). Characteristics of Sulfobacillus acidophilus sp. nov. and other moderately thermophilic mineral-sulphideoxidizing bacteria. Microbiology 142, 775-783.

Ram, R. J., VerBerkmoes, N., Thelen, M. P., Tyson, G. W., Baker, B. J., Blake, R. C. II, Shah, M., Hettich, R., and Banfield, J. F. (2005). Community proteomics of a natural microbial biofilm. Science 308, 1915-1920.

Segerer, A., Neuner, A., Kristjansson, J. K., and Stetter, K. O. (1986) Acidianus infernus gen. nov., sp. nov., and Acidianus brierleyi comb. nov.: facultatively aerobic, extremely acidophilic, thermophilic sulfur-metabolizing archaebacteria. Int. J. Syst. Bacteriol. 36, 559-564.

Shibata, K., Benson, A. A., and Calvin, M. (1954). The absorption 
spectra of suspensions of living microorganisms. Biochim. Biophys. Acta 15,461-470.

Siezen, R. J., and Wilson, G. (2009). Bioleaching genomics. Microb. Biotechnol. 2, 297-303.

Singer, S. W., Chan, C. S., Zemla, A., VerBerkmoes, N. C., Hwang, M., Hettlich, R. L., Banfield, J. L., and Thelen, M. P. (2008). Characterization of cytochrome 579, an unusual cytochrome isolated from an iron-oxidizing microbial community. Appl. Environ. Microbiol. 74, 4454-4462.

Takai, M., Kamimura, K., and Sugio, T. (2001). A new iron oxidase from a moderately thermophilic iron oxidizing bacterium strain TI-1. Eur. J. Biochem. 268 , 1653-1658.
Tuovinen, O. H., and Kelly, D. P. (1973). Studies on the growth of Thiobacillus ferrooxidans. I. Use of membrane filters and ferrous iron agar to determine viable numbers, and comparison with $14 \mathrm{CO}_{2}$ fixation and iron oxidation as measures of growth. Arch. Microbiol. 22, 285-296.

Valdes, J., Pedroso, I., Quatrini, R., Tettelin, H., Blake, R. C. II, Malek, J., Eisen, J. A., and Holmes, D. S. (2008). Modeling Acidithiobacillus ferrooxidans metabolism: from genome sequence to industrial applications. $B M C$ Genomics 9, 597. doi:10.1186/14712164-9-597

Yarzábal, A., Appia-Ayme, C., Ratouchniak, J., and Bonnefoy, V. (2004). Regulation of the expression of the
Acidithiobacillus ferrooxidans rus operon encoding two cytochromes $c$, a cytochrome oxidase and rusticyanin. Microbiology 150, 2113-2123.

Yarzábal, A., Brasseur, G., Appia-Ayme, C., Ratchouchniak, J., Lund, K. Lemesle-Meunier, D., DeMoss, J. A., and Bonnefoy, V. (2002). The high molecular weight cytochrome c Cyc2 of Acidithiobacillus ferrooxidans is an outer membrane protein. J. Bacteriol. 184, 313-317.

Conflict of Interest Statement: The authors declare that the research was conducted in the absence of any commercial or financial relationships that could be construed as a potential conflict of interest.
Received: 22 November 2011; accepted: 21 March 2012; published online: 12 April 2012.

Citation: Blake II RC and Griff $M N$ (2012) In situ spectroscopy on intact Leptospirillum ferrooxidans reveals that reduced cytochrome 579 is an obligatory intermediate in the aerobic iron respiratory chain. Front. Microbio. 3:136. doi 10.3389/fmicb.2012.00136

This article was submitted to Frontiers in Microbiological Chemistry, a specialty of Frontiers in Microbiology.

Copyright $(5) 2012$ Blake II and Griff. Thi is an open-access article distributed under the terms of the Creative Commons Attribution Non Commercial License, which permits non-commercial use, distribution, and reproduction in other forums, provided the original authors and source are credited. 